\title{
Simultaneous Development of Three Different Neoplasms of Trichilemmoma, Desmoplastic Trichilemmoma and Basal Cell Carcinoma Arising from Nevus Sebaceus
}

\author{
Chi An Lee ${ }^{1}$, \\ Seok Joo Kang ${ }^{1}$, \\ Seong Pin Jeon ${ }^{1}$, \\ Hook Sun ${ }^{1}$, \\ Mi Seon Kang ${ }^{2}$ \\ Departments of ${ }^{I}$ Plastic and Reconstructive \\ Surgery and ${ }^{2}$ Pathology, Busan-Baik Hospital, \\ Inje University School of Medicine, Busan, \\ Korea
}

No potential conflict of interest relevant to this article was reported.

\begin{abstract}
Nevus sebaceus is a hamartoma of the sebaceous gland that occurs congenitally, from which various secondary tumors can arise with a prevalence of $5 \%-6 \%$. Benign neoplasms commonly arise from nevus sebaceous, but they have a very low malignant potential. Two neoplasms may occasionally arise within the same lesion, but it is rare for three or more neoplasms to occur in a nevus sebaceus simultaneously. A 61-year-old male patient was admitted to our hospital for a $4 \mathrm{~cm} \times 2.5 \mathrm{~cm}$ growing tumor in a verrucous form arising within a periauricular nevus sebaceus in the post auricle of the left ear that had developed 30 years earlier. The nodule was diagnosed as 3 different types of tumors: trichilemmoma, desmoplastic trichilemmoma, and basal cell carcinoma. To our knowledge, this is the first report of the coexistence of three different tumors arising from nevus sebaceous. It contain malignant neoplasm also. Surgeons should be aware of the need for close monitoring and early complete surgical excision of sebaceous nevus in order to improve patient outcomes.

Keywords: Nevus sebaceous / Hamartoma / Trichilemmoma / Basal cell carcinoma / Adnexal neoplasm / Skin tumor
\end{abstract}

\section{INTRODUCTION}

Nevus sebaceus is a relatively infrequent congenital skin hamartoma of abnormal cutaneous structures, from which various secondary tumors can arise with a prevalence of $5 \%-6 \%$. Most of the secondary tumors arising within nevus sebaceus are benign [1]. Syringocystadenomapapilliferum andtrichoblastoma are the most common benign tumors associated with nevus sebaceus, while the most common malignant neoplasm secondary to nevus sebaceus is basal cell carcinoma (BCC), followed by squamous cell carcinoma (SCC) and sebaceous carcinoma [2]. Two neoplasms may occasionally arise within the same lesion, but it is rare for three or more neoplasms to occur in a nevus sebaceus simultane-

Correspondence: Seok Joo Kang

Department of Plastic and Reconstructive Surgery, Busan Baik Hospital, Inje University School of Medicine, 75 Bokji-ro, Busanjin-gu, Busan 47392, Korea

E-mail: sonydr@naver.com

Received December 7, 2016 / Revised February 8, 2017 / Accepted February 9, 2017 ously. We report a rare case of multiple tumors including trichilemmoma, desmoplastic trichilemmoma, and basal cell carcinoma arising within a growing periauricular nevus sebaceus.

\section{CASE REPORT}

This study was reviewed and approved by the Ethics Review Board of the Inje University Health Center.

A 61-year-old man was admitted to our hospital for a tumor in the post auricle of the left ear. The patient developed a nodule in the congenital nevus in the post auricle 30 years earlier, which increased in size over time. The nodule measured $4 \mathrm{~cm} \times 2.5 \mathrm{~cm}$, and was indolent and in a verrucous form (Fig. 1).

The nodule was diagnosed as trichilemmoma arising within nevus sebaceus based on a preoperative biopsy. The tumor was completely resected with a $0.5 \mathrm{~cm}$ margin under general anesthesia. Frozen biopsy of resected tissue during surgery confirmed 


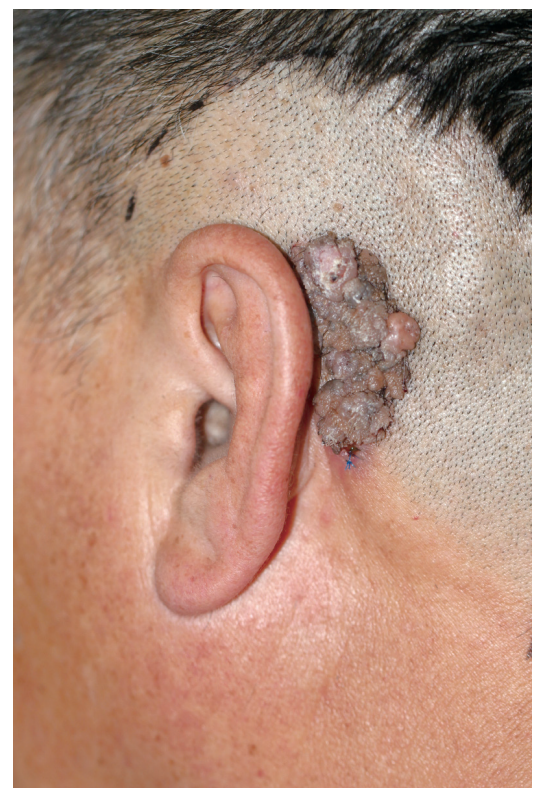

Fig. 1. Preoperative appearance. A $4 \mathrm{~cm} \times 2.5 \mathrm{~cm}$ verrucous nodule in the post auricle arising from the congenital nevus in a 61 year old male patient.

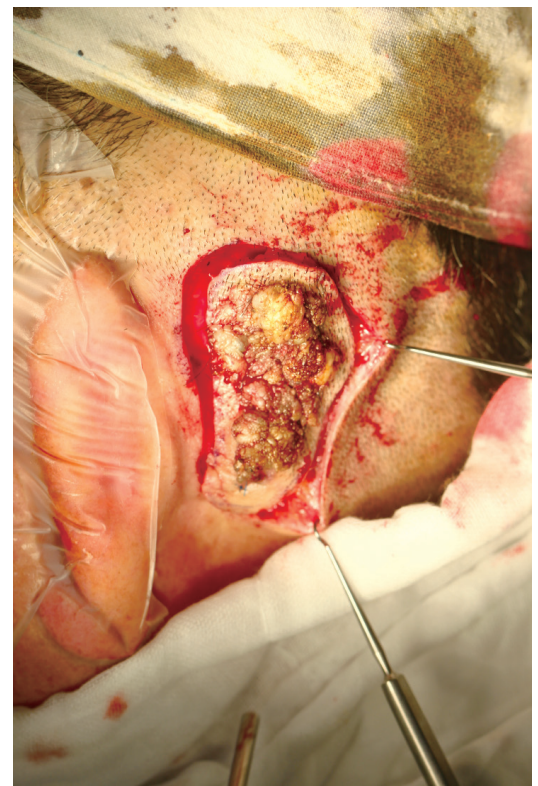

Fig. 2. Intraoperative view. Following Mohs surgery, the skin defect of $5 \mathrm{~cm} \times 3.5 \mathrm{~cm}$ was repaired via rotational flap.

that the margins were all clear. The defect in the lesion area was repaired by rotating the surrounding scalp skin (Figs. 2, 3).

Histopathologic findings of the resected lesion showed 3 different types of tumors: trichilemmoma, desmoplastic trichilemmo-

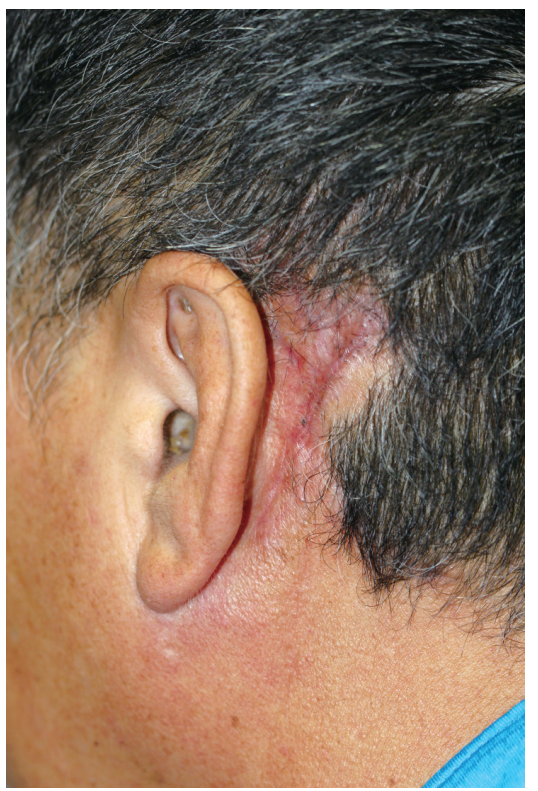

Fig. 3. Postoperative appearance. Postoperative photograph showing a mild depressed and erythematous scar without recurrence at 6 months after surgery.

ma, and basal cell carcinoma. Trichilemmoma showed multinodular proliferation of uniform polyhedral cells with a clear cytoplasm. The tumor nodules were well-defined and revealed peripheral palisading of basal cells and a thick, eosinophilic basement membrane (Fig. 4A). Some of the tumor nodules were irregularly interdigitating between hyalinized fibrous tissues and appeared like stromal infiltration. However, the tumor cells were benign-looking and were considered to be a desmoplastic variant of trichilemmoma (Fig. 4B). Superficially located, anastomosing cords of monomorphic basaloid cells and keratinocytes connecting to the epidermal surface and hyalinized collagenous stroma were also observed. This lesion showed melanin pigments and was diagnosed as BCC (Fig. 4C).

\section{DISCUSSION}

Nevus sebaceus is a relatively uncommon among other congenital skin hamartoma of abnormalities of the sebaceous glands, hair follicles, and epidermis with an incidence of $0.05 \%-1 \%$. A variety of secondary neoplastic transformations are observed in $21.4 \%$ of cases, with benign neoplasms accounting for $18.9 \%$ of these. The 

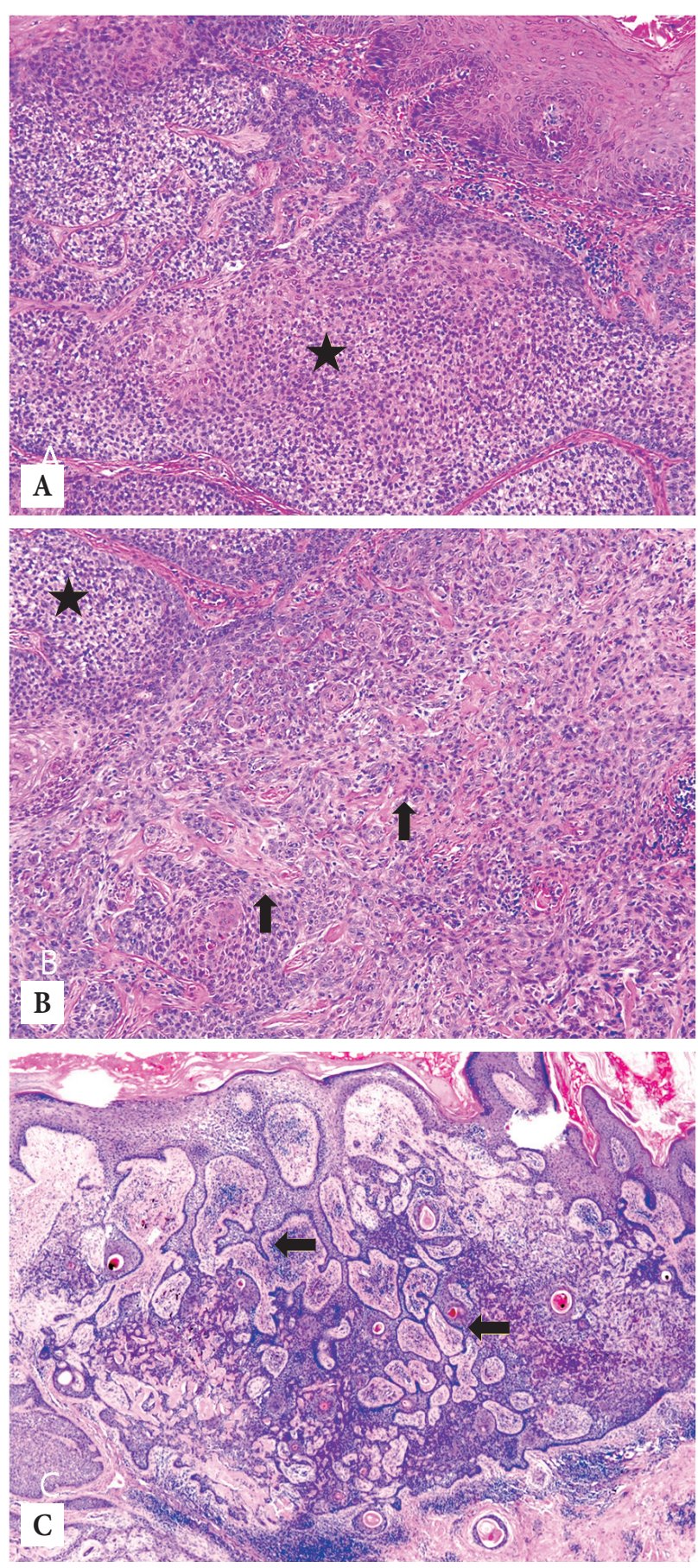

Fig. 4. Histopathologic findings. (A). Trichilemmoma (asterisk) shows well-defined lobulated proliferation of polyhedral cells with clear or eosinophilic cytoplasm within the open circle (H\&E, $\times 100)$. (B) Desmoplastic trichilemmoma reveals interdigitating strands of tumor cells in the hyalinized fibrous stroma (vertical arrows) with trichilemmoma (asterisk) (H\&E, $\times 100)$. (C) Basal cell carcinoma shows elongated branching strands of basaloid cells and keratinocytes in reticulated arrays with hyperpigmentation (horizontal arrows) (H\&E, $\times 100)$. commonly arising benign tumors from nevus sebaceus include trichoblastoma, syringocystadenoma papilliferum, trichilemmoma, sebaceoma, and adenomyoepithelioma; BCC is the most common malignant neoplasm associated with nevus sebaceous, followed by SCC and sebaceous carcinoma [2]. Tumors rarely arise within the same lesion. Gupta and Gupta [3] reported a case of BCC and syringocystadenoma papilliferum arising in a nevus sebaceous. Stavrianeas et al. [4] reported the coexistence of BCC, a syringocystadenoma papilliferum, and a proliferating trichilemmal cyst in a nevus sebaceous. However, it is extremely rare for three or more neoplasms to occursimultaneously within a nevus sebaceous [5].

In the present report, three distinct tumors arising from a nevus sebaceus, trichilemmoma, desmoplastic trichilemmoma, and BCC, were confirmed by the biopsy results. Trichilemmoma are benign adnexal neoplasms derived from the hair follicle unit exhibiting differentiation toward the outer root sheath of the pilosebaceous follicular epithelium. Trichilemmomas are closely associated with the epidermis [6], and have been reported to arise within nevus sebaceous. Desmoplastic trichilemmoma is an uncommon cutaneous variant of trichilemmoma. It is most frequently located on the face, usually affecting middle-aged men. Additionally, it is a benign neoplasm with no reported recurrence after surgical excision, and has been reported to occur within a nevus sebaceus and also in association with BCC. Because desmoplastic trichilemmoma is such an uncommon neoplasm rarely observed by pathologists and can be easily confused with BCC, complete excision of the lesion is usually recommended [7]. BCC is the most common form of skin cancer in adults. Its association with nevus sebaceus has been documented, and several reviews have reported approximately $10 \%-20 \%$ of malignant transformation of untreated nevus sebaceus in adulthood. Significant sun exposure is a well-recognized risk factor for development of BCC [8]. The patient in this case was a sailor with constant sun exposure for several decades.

Occurrence of multiple benign and malignant neoplasms arising from the nevus sebaceus in our patient suggests prophylactic excision and close clinical surveillance afterwards for new growth or recurrence are required. To our knowledge, this is the first re- 
port of the coexistence of trichilemmoma, desmoplastic trichilemmoma, and BCC arising from nevus sebaceus for which complete excision was performed, and thus far, it has not recurred.

Surgeons should be aware of the development of multiple benign and malignant tumors arising from a nevus sebaceous and appropriate diagnosis and management should be planned for the patient. This report will be helpful for further study of diseases developing from nevus sebaceous.

\section{REFERENCES}

1. Izumi M, Tang X, Chiu CS, Nagai T, Matsubayashi J, Iwaya K, et al. Ten cases of sebaceous carcinoma arising in nevus sebaceus. J Dermatol 2008;35:704-11.

2. Idriss MH, Elston DM. Secondary neoplasms associated with nevus sebaceus of Jadassohn: a study of 707 cases. J Am Acad Dermatol 2014;70:332-7.
3. Gupta SK, Gupta V. Basal cell carcinoma and syringocystadenoma papilliferum arising in nevus sebaceous on face-a rare entity. Indian J Dermatol 2015;60:637.

4. Stavrianeas NG, Katoulis AC, Stratigeas NP, Karagianni IN, PatertouStavrianea M, Varelzidis AG. Development of multiple tumors in a sebaceous nevus of Jadassohn. Dermatology 1997;195:155-8.

5. Miller CJ, Ioffreda MD, Billingsley EM. Sebaceous carcinoma, basal cell carcinoma, trichoadenoma, trichoblastoma, and syringocystadenoma papilliferum arising within a nevus sebaceus. Dermatol Surg 2004;30:1546-9.

6. Stowman AM, Griffin MM, Kanner WA, Tchernev G, Chokoeva AA, Wollina U, et al. Coexistent trichilemmoma and trichoblastoma without associated nevus sebaceus. J Biol Regul Homeost Agents 2016;30:17-20.

7. Schweiger E, Spann CT, Weinberg JM, Ross B. A case of desmoplastic trichilemmoma of the lip treated with Mohs surgery. Dermatol Surg 2004;30:1062-4.

8. Turner CD, Shea CR, Rosoff PM. Basal cell carcinoma originating from a nevus sebaceus on the scalp of a 7-year-old boy. J Pediatr Hematol Oncol 2001;23:247-9. 